07.2,07.3

\title{
Мощные высокоскоростные фотодиоды Шоттки для аналоговых волоконно-оптических линий передачи СВЧ-сигналов
}

\author{
() А.Л. Чиж ${ }^{1}$, К.Б. Микитчук ${ }^{1}$, К.С. Журавлев ${ }^{2,3, \uparrow, ~ Д . В . ~ Д м и т р и е в ~}{ }^{2,3}$, А.И. Торопов ${ }^{2}$, Н.А. Валишева ${ }^{2}$, \\ М.С. Аксенов ${ }^{2}$, А.М. Гилинский ${ }^{2}$, И.Б. Чистохин ${ }^{2}$ \\ ${ }^{1}$ ГНПО „Оптика, оптоэлектроника и лазерная техника“ НАН Беларуси, Минск, Беларусь \\ ${ }^{2}$ Институт ффизики полупроводников им. А.В. Ржанова СО РАН, Новосибирск, Россия \\ ${ }^{3}$ Новосибирский государственный университет, Новосибирск, Россия \\ 『E-mail: zhur@isp.nsc.ru
}

Поступило в Редакцию 4 марта 2019г.

В окончательной редакции 17 апреля 2019г.

Принято к публикации 17 апреля 2019г.

\begin{abstract}
Разработаны конструкция и технология изготовления мощных СВЧ-фотодиодов Шоттки с микрополосковыми выводами на основе двойной гетероструктуры InAlAs/InGaAs. Рабочая частота фотодиодов диаметром $15 \mu \mathrm{m}$ составляет более $25 \mathrm{GHz}$, а максимальная выходная СВЧ-мощность - свыше $50 \mathrm{~mW}$ на частоте $20 \mathrm{GHz}$, что позволяет применять такие фотодиоды в аналоговых волоконно-оптических линиях передачи СВЧ-сигналов, а также для генерации и обработки СВЧ-сигналов оптическими методами в системах радиолокации и измерительной СВЧ-техники.
\end{abstract}

Ключевые слова: мощные СВЧ-фотодиоды, барьер Шоттки, гетероструктуры InAlAs/InGaAs.

DOI: 10.21883/PJTF.2019.14.48026.17764

Развитие волоконно-оптических технологий открыло новые возможности для создания систем радиофотоники, в которых генерация, передача и обработка СВЧсигналов осуществляются оптическими и оптоэлектронными методами. Такие системы и устройства обладают характеристиками, недостижимыми в случае традиционных электронных средств [1]. Аналоговые волоконнооптические линии передачи являются базовыми элементами систем радиофотоники и выступают в качестве альтернативы коаксиальным кабелям при передаче СВЧ-сигналов на расстояние более $10 \mathrm{~m}$ вследствие сверхнизких потерь в оптическом волокне (менее $0.0004 \mathrm{~dB} / \mathrm{m})$ по сравнению с потерями в коаксиальном кабеле (около $1 \mathrm{~dB} / \mathrm{m}$ для частоты $18 \mathrm{GHz}[2]$ ). Для использования преимуществ волоконно-оптических линий передачи СВЧ-сигналов (низких потерь, сверхширокой полосы пропускания, устойчивости к помехам, малой массы [3]) требуется применение мощных высокоскоростных фотодиодов [4]. Как известно, при высокой мощности оптического излучения для фотодиодов характерно насыщение фототока, обусловленное влиянием пространственного заряда, а также эффектом саморазогрева при протекании фототока [5-8]. Это указывает на необходимость оптимизации отвода тепла от фотодиода и снижения влияния эффекта пространственного заряда.

В настоящей работе представлена конструкция мощных СВЧ-фотодиодов с барьером Шоттки для применения в аналоговых волоконно-оптических линиях передачи СВЧ-сигналов с широким динамическим диапазоном.

Фотодиоды изготавливаются на основе двойной гетероструктуры InAlAs/InGaAs, конструкция которой представлена в таблице. Гетероструктура выращивает- ся на подложке полуизолирующего $\operatorname{InP}(001)$ методом молекулярно-лучевой эпитаксии и содержит контактный слой $n^{+}-\mathrm{In}_{0.52} \mathrm{~A} 1_{0.48} \mathrm{As}$, легированный поглощающий слой $n^{+}-\operatorname{In}_{0.53} \mathrm{Ga}_{0.47} \mathrm{As}$ малой толщины, нелегированные поглощающий слой $n^{0}-\mathrm{In}_{0.53} \mathrm{Ga}_{0.47} \mathrm{As}$, варизонный слой $n^{0}$-InAlGaAs, барьерный слой $n^{0}$-InAlAs и защитный слой $n^{0}$-InGaAs. Контактный слой $n^{+}$-InAlAs используется для формирования омического контакта. Тонкий поглощающий слой $n^{+}$-InGaAs и варизонный слой $n^{0}$-InAlGaAs используются для устранения эф-

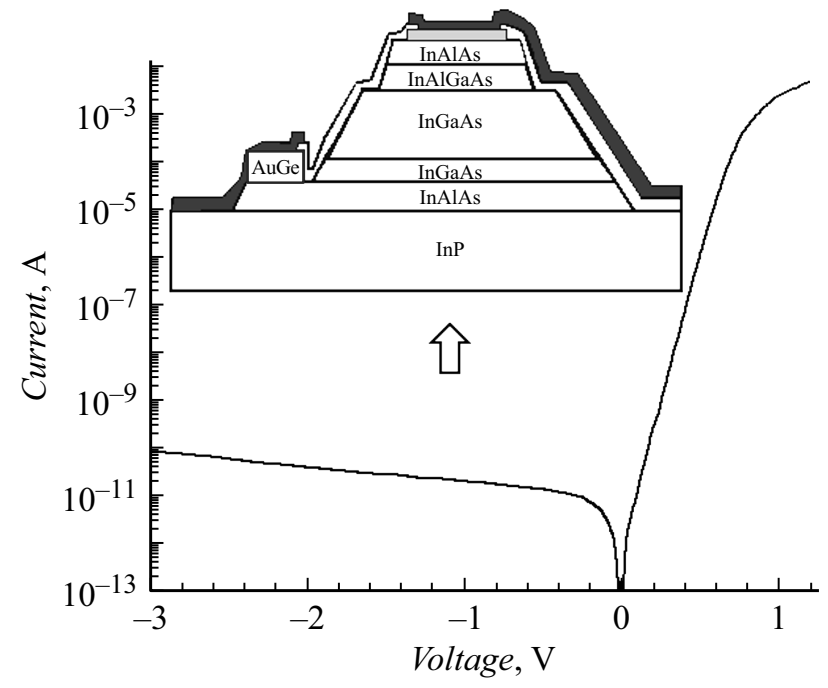

Рис. 1. Вольт-амперная характеристика мощного СВЧ-фотодиода Шоттки с диаметром $15 \mu \mathrm{m}$. На вставке схематическое изображение меза-структуры фотодиода (не в масштабе). Направление подачи оптического излучения указано стрелкой. 

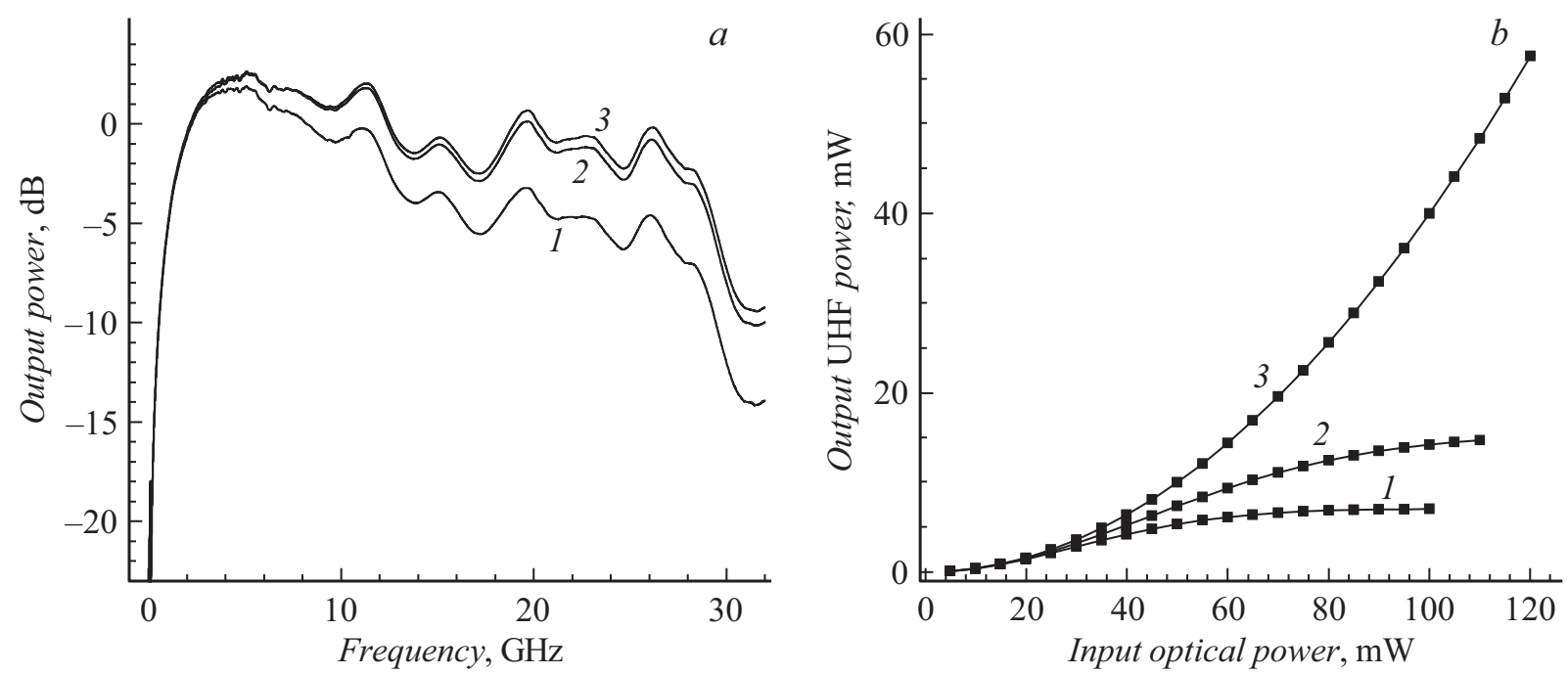

Рис. 2. $a$ - амплитудно-частотная характеристика СВЧ-фотодиода Шоттки InGaAs/InAlAs с диаметром меза-структуры $15 \mu$ m, установленного в копланарную СВЧ-линию, при различных напряжениях обратного смещения; $b$ - зависимость мощности СВЧ-сигнала на выходе фотодиода от входной оптической мощности при $100 \%$ глубине модуляции на частоте $20 \mathrm{GHz}$, измеренная при различных напряжениях обратного смещения. Напряжение смещения, V: $1-1,2-2,3-3$.

Конструкция гетероструктуры для изготовления фотодиодов

\begin{tabular}{l|c|c}
\hline \multicolumn{1}{c|}{ Состав слоя } & Толщина, $\mathrm{nm}$ & $\begin{array}{c}\text { Уровень } \\
\text { легирования, } \mathrm{cm}^{-3}\end{array}$ \\
\hline$n^{0}-\mathrm{In}_{0.53} \mathrm{Ga}_{0.47} \mathrm{As}$ & 30 & Остаточное \\
$n^{0}-\mathrm{In}_{0.52} \mathrm{Al}_{0.48} \mathrm{As}$ & 30 & $\gg$ \\
$n^{0}-\mathrm{InAlGaAs}^{0} \mathrm{Ga}-\mathrm{In}_{0.53} \mathrm{Ga}_{0.47} \mathrm{As}$ & 30 & $>$ \\
$n^{+}-\mathrm{In}_{0.53} \mathrm{Ga}_{0.47} \mathrm{As}$ & 50 & $5 \cdot 10^{14}$ \\
$n^{+}-\mathrm{In}_{0.52} \mathrm{Al}_{0.48} \mathrm{As}$ & 300 & $5 \cdot 10^{18}$ \\
Подложки InP & - & -
\end{tabular}

фекта накопления носителей заряда на гетерограницах InAlAs/InGaAs, снижающего предельную рабочую частоту фотодиодов. Барьер Шоттки формируется напылением слоев $\mathrm{Ti} / \mathrm{Au}$ на широкозонный слой $n^{0}$-InAlAs, что обеспечивает увеличение высоты потенциального барьера и снижение величины темнового тока прибора при обратном смещении [9]. Для защиты от окисления алюминийсодержащего слоя $n^{0}$-InAlAs до формирования барьера Шоттки применяется защитный слой $n^{0}$-InGaAs.

Фотодиод содержит меза-структуру с барьером Шоттки и массивными металлическими контактами толщиной $5 \mu \mathrm{m}$, обеспечивающими высокую электро- и теплопроводность. Такая конструкция фотодиода обладает низким тепловым сопротивлением благодаря отводу тепла из области пространственного заряда через оба контакта [10]. Меза-структура фотодиода схематично показана на вставке к рис. 1. Контакты фотодиода выполняются в виде микрополосковых выводов, с помощью которых обеспечивается монтаж фотодиода методом перевернутого кристалла непосредственно на копланар- ную СВЧ-линию передачи, являющуюся также теплоотводом. Для пассивации межслоевой изоляции и поверхности структуры используются слои диэлектриков. Подача оптического излучения в фоточувствительную область фотодиодов производится через полуизолирующую подложку InP, прозрачную в рабочем спектральном диапазоне 1.26-1.65 $\mu \mathrm{m}$ распространенных волоконнооптических систем на основе волокон $\mathrm{SiO}_{x} / \mathrm{SiO}_{y}$. Для снижения величины коэффициента отражения от поверхности фотодиода на подложку наносится просветляющее покрытие на длину волны $1.55 \mu \mathrm{m}$.

Типичная вольт-амперная характеристика фотодиода с диаметром меза-структуры $15 \mu \mathrm{m}$ приведена на рис. 1. Темновой ток фотодиодов при обратном напряжении 2-3 V равен 0.05-0.2 nA. Высота барьера Шоттки фотодиодов, определенная по прямой ветви вольт-амперной характеристики, составляет $0.7 \mathrm{~V}$. Емкость фотодиодов при напряжении обратного смещения $2 \mathrm{~V}$ равна 100-110 fF, что при использовании линии передачи с волновым сопротивлением $50 \Omega$ соответствует полосе рабочих частот $30 \mathrm{GHz}$. Чувствительность фотодиодов на длине волны излучения $1.55 \mu \mathrm{m}$ составляет $0.40-0.55 \mathrm{~A} / \mathrm{W}$.

На рис. 2, а приведена амплитудно-частотная характеристика (АЧХ) СВЧ-фотодиода Шоттки, установленного в копланарную СВЧ-линию с волновым сопротивлением $50 \Omega$, при различных напряжениях обратного смещения. Спад АЧХ на низких частотах обусловлен используемой цепью подачи смещения фотодиода, а неравномерности АЧХ связаны с неполным согласованием импеданса фотодиода и линии передачи. Полоса рабочих частот фотодиода на уровне $-3 \mathrm{~dB}$ составляет $28 \mathrm{GHz}$. На рис. 2,b показана зависимость выходной мощности 


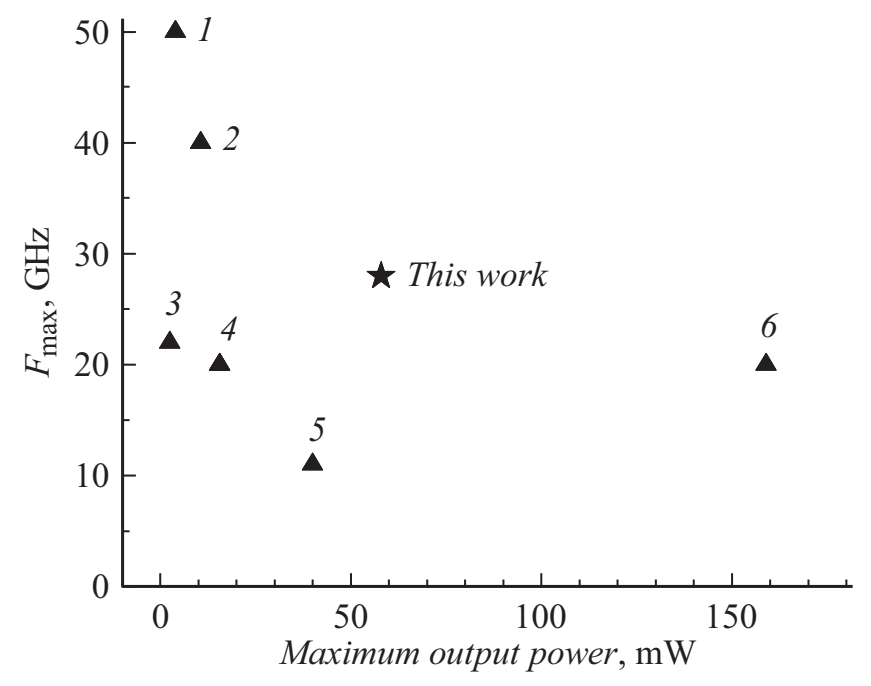

Рис. 3. Максимальная выходная мощность и полоса рабочих частот $F_{\max }$ коммерчески доступных моделей СВЧ-фотодиодов $(1-6)$ и фотодиодов, разработанных в настоящей работе. Позиции 1-6 соответствуют фотодиодам Finisar HPDV2120R (1), Apic Corp. ARx40 (2), Discovery Semiconductor DSC30S (3), Apic Corp. ARx20 и Optilab PH-20-HP-M (4), Apic Corp. ARx10 (5) и Finisar VPDV2120 (6).

СВЧ-фотодиода, установленного в копланарную СВЧлинию, от входной оптической мощности при 100\% глубине модуляции на частоте $20 \mathrm{GHz}$ для различных напряжений обратного смещения. Как видно из рисунка, увеличение напряжения смещения приводит к увеличению максимальной выходной СВЧ-мощности. При напряжении смещения $3 \mathrm{~V}$ выходная СВЧ-мощность квадратично зависит от входной оптической мощности. Максимальное значение выходной СВЧ-мощности фотодиода составляет $58 \mathrm{~mW}$. При напряжении смещения $3 \mathrm{~V}$ и входной оптической мощности свыше $120 \mathrm{~mW}$ наблюдается необратимый пробой фотодиодов.

На рис. 3 приведено сравнение параметров максимальной выходной мощности и полосы рабочих частот изготовленных фотодиодов с характеристиками ряда коммерчески доступных моделей СВЧ-фотодиодов. Величина максимальной выходной мощности коммерческих образцов указывается в соответствии с данными производителей либо (при отсутствии результатов прямых измерений) рассчитана из приводимых значений максимального выходного постоянного тока для сопротивления нагрузки $50 \Omega$.

Таким образом, достигнутый уровень полосы рабочих частот и выходной мощности разработанных СВЧ-фотодиодов на основе гетероструктуры InAlAs/InGaAs позволяет использовать их в аналоговых волоконно-оптических линиях передачи СВЧ-сигналов с широким линейным динамическим диапазоном, а также для генерации и обработки СВЧ-сигналов оптическими методами в системах радиолокации, радиосвязи и измерительной СВЧ-техники.

\section{Финансирование работы}

Работа выполнена в рамках государственного задания 0306-2019-00008 „Гетероструктуры на основе материалов $\mathrm{A}_{3} \mathrm{~B}_{5}$ для СВЧ-электроники и СВЧ-фотоэлектроники“.

\section{Конфликт интересов}

Авторы заявляют, что у них нет конфликта интересов.

\section{Список литературы}

[1] Seeds A.J., Williams K.J. // J. Lightwave Technol. 2006. V. 24. N 12. P. 4628-4641.

[2] Малышев С.А., Чиж А.Л., Микитчук К.Б. Волоконнооптические лазерные и фотодиодные модули СВЧдиапазона и системы радиофотоники на их основе // Материалы 4-й Всерос. конф. „Электроника и микроэлектроника СВЧ“. СПб., Россия, 2015. С. 10-18.

[3] Ridgway R.W., Dohrman C.L., Conway J.A. // IEEE/OSA J. Lightwave Technol. 2014. V. 32. N 20. P. 3428-3439.

[4] Чистохин И.Б., Журавлев К.С. // Успехи прикладной физики. 2015. Т. 3. № 1. С. 85-94.

[5] Liu P.L., Williams K.J., Frankel M.Y., Esman R.D. // IEEE Trans. Microwave Theory Tech. 1999. V. 47. N 7. P. $1297-$ 1303.

[6] Beling A., Xie X., Campbell J.C. // Optica. 2016. V. 3. N 3. P. 328-338.

[7] Williams K.J., Esman R.D. // J. Lightwave Technol. 1999. V. 17. N 8. P. 1443-1454.

[8] Malyshev S.A., Chizh A.L., Vasileuski Yu.G. // J. Lightwave Technol. 2008. V. 26. N 15. P. 2732-2739.

[9] Chistokhin I.B., Aksenov M.S., Valisheva N.A., Dmitriev D.V., Kovchavtsev A.P., Gutakovskii A.K., Prosvirin I.P., Zhuravlev K.S. // Mater. Sci. Semicond. Proc. 2018. V. 74. P. 193-198.

[10] Chizh A., Malyshev S., Mikitchuk K. High-speed highpower InAlAs/InGaAs/InP Schottky photodiode // IEEE Int. Topical Meeting on microwave photonics (MWP2015). Paphos, Cyprus, 2015. P. 1-4. 